\title{
MJFAS MALAYSIAN JUURNAL OF

\section{High voltage powder spray coating as a new method for the preparation of carbon-titania coated stainless steel}

\author{
Farah Syuhada Abdul Halim ${ }^{a, b}$, Sheela Chandren ${ }^{b}$, Madzlan Aziz b , Leaw Wai Loon ${ }^{a}$, \\ Hadi Nur ${ }^{a, b^{*}}$ \\ a Centre for Sustainable Nanomaterials, Ibnu Sina Institute for Scientific and Industrial Research, Universiti Teknologi Malaysia, Skudai 81310, \\ Johor, Malaysia \\ b Department of Chemistry, Faculty of Science, Universiti Teknologi Malaysia, 81310 UTM Johor Bahru, Johor, Malaysia
}

* Corresponding author: hadi@kimia.fs.utm.my

\section{Article history}

Received 2 November 2017

Accepted 20 December 2017

\section{Graphical abstract}

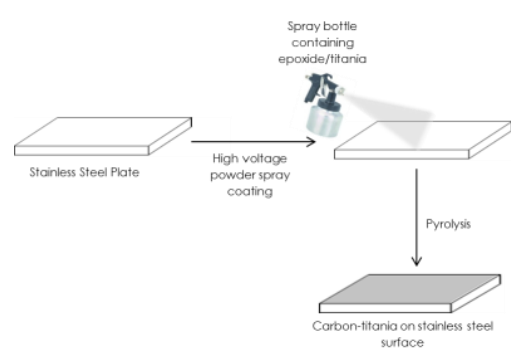

\begin{abstract}
High voltage powder spray coating (HVPSC) is one of the methods used for coating substrate with polymer powder in industries. This study utilizes HVPSC as a new deposition method of carbon-based powdered materials on stainless steel. Carbon-titania $\left(\mathrm{C} / \mathrm{TiO}_{2}\right)$ coated stainless steel was successfully prepared from the mixture of epoxide and titania powder, sprayed onto stainless steel plate using HVPSC, followed by pyrolysis at $300{ }^{\circ} \mathrm{C}$ under nitrogen atmosphere. The functional group of $\mathrm{C} / \mathrm{TiO}_{2}$ was confirmed by Fourier transform infrared (FTIR) spectroscopy, where the FTIR spectrum showed the presence of $\mathrm{C}-\mathrm{H} \mathrm{sp}{ }^{3}, \mathrm{C}=\mathrm{O}, \mathrm{C}-\mathrm{O}$, and $\mathrm{Ti}-\mathrm{O}$ peaks. The morphology of the $\mathrm{C} / \mathrm{TiO}_{2}$ sample studied using field emission scanning electron microscopy (FESEM) clearly shows that the particles of $\mathrm{TiO}_{2}$ were coated with carbon on their surface. The coating performance was evaluated through the abrasion test and showed no weight loss. Adhesion of $\mathrm{C} / \mathrm{TiO}_{2}$ coating was also tested in the peel adhesion test and the result showed that the attachment of $\mathrm{C} / \mathrm{TiO}_{2}$ on the stainless steel is very strong. It has been proven that the HVPSC method is not only a simple technique to coat materials but also a very durable one.
\end{abstract}

Keywords: Carbon, titania, stainless steel, coating and high voltage powder spray coating

\section{INTRODUCTION}

Studies on the immobilization of potential materials onto the substrate have been gradually increasing. In the aspect of immobilization form, thin films and films coating have been widely applied in solar cells, pharmaceutical, photocatalysis, and preferred application [1-3]. A variety of potential coating materials can be selected depending on the study interest such as modification of carbon (C) with a metal oxide for the degradation of dye, photoactivity, and removal of inorganic and organic pollutants [4-7]. $\mathrm{C}$ is one of the topmost selected materials because of its useful properties, such as high electrical and thermal conductivity, high chemical stability, high lubricity, nontoxicty and resistivity towards radiation [8]. Although $\mathrm{C}$ is a widely used substance, the enhancement of $\mathrm{C}$ functionalities is still required. Metal oxide, such as $\mathrm{TiO}_{2}$, can act as an additive in the modification of carbon-based materials. This is due to the unique properties and good performance of metal oxides. In the previous studies, addition of $\mathrm{TiO}_{2}$ has veen extensively utilized for epoxies, plastics, rubbers and so forth [9-13].

Based on previous works, sol-gel, chemical vapor deposition (CVD), oxidation of titanium plate, and plasma spraying are the common deposition techniques of materials on substrates [14-15]. Sol gel method is a relatively easy procedure. However, the material might suffer large volume shrinkage and cracking during drying [16]. In addition, difficulty in producing large surface coating due to low formation speed and bonding strength are also the drawbacks of solgel and CVD methods [14]. Apart from the mention methods, high voltage powder spray coating (HVPSC) is an established method that has been used in finishing industry, paint industry and pharmaceuticul for polymer coating [3,19]. In industry, this method is ordinarily utilized for polymer powder coating [18]. Powder coating is an efficient and highly effective process that introduces powder material as a medium and requires polymer resin as the adhesive to metal substrates [19]. Generally, HVPSC utilizes the electrostatic spraying concept that uses high voltage gun, which produces electric force to ensure that the powders emitted from the nozzle can reach the grounded metal substrate's surface by electrostatic interaction. Based on its charging principle with a constant supply of electrostatic charge, electrostatic charging will generate powders with free electrons onto the substrate [19].

In the present work, carbon-titania $\left(\mathrm{C} / \mathrm{TiO}_{2}\right)$ coated on stainless steel was prepared by the aforementioned HVPSC method. To the best of the authors' knowledge, there have not been any studies regarding the application of HVPSC as the method to coat carbonbased material onto the substrate. For further understanding, the coating performance in term of its durability and resistance were studied, in order to open possibilities for future applications.

\section{EXPERIMENTAL}

\section{Materials}

The materials used in this research were epoxide powder (Oxyplast PR12) as the carbon precursor, commercial titania powder (Sigma-Aldrich), ethanol (Qrec, $99.8 \%$ ), acetone (Qrec), distilled water, stainless steel plate (SAE 304), molecular sieve beads (SigmaAldrich) and adhesive double-sided tape (Unicorn double-sided foam tape, GP-99). 


\section{Coating preparation}

$\mathrm{C}$ and $\mathrm{C} / \mathrm{TiO}_{2}$ coating was prepared by the deposition of powder material method of HVPSC. For coating purpose, stainless steel plates were cut into $6 \mathrm{~cm} \times 2.5 \mathrm{~cm}$ size, cleaned with ethanol and acetone to remove any contaminants on the plates surface. For $\mathrm{C} / \mathrm{TiO}_{2}$ sample, epoxide and $\mathrm{TiO}_{2}$ powder with a weight ratio of $80: 20 \mathrm{wt} \%$ were homogeneously mixed by grinding the powders to a very fine size. The mixed powders were then loaded into the spray bottle equipped with the high voltage spray powder machine at a voltage of $50 \mathrm{kV}$ for spraying process. For $\mathrm{C}$ sample, the same procedure was repeated but with only using epoxide powder without the addition of $\mathrm{TiO}_{2}$ powder. The successful coated plates then went through curing process, pyrolysed under nitrogen atmosphere at the temperature $300^{\circ} \mathrm{C}$ for an hour. The properties of the coated stainless steel samples produced by HVPSC were then further characterized.

\section{Samples characterization}

The thickness of the coatings has determined using a surface profiler instrument from KLA/TENCOR in ALPHA STEP IQ model. The samples were run under Low force measurements at 0.03 to 15 mg with step height repeatability of $5 \AA$ on a $1 \mu \mathrm{m}$ step. Functional groups of the samples were identified using a Perkin-Elmer Fourier transform infrared (FTIR) spectroscopy with a spectral resolution of $2 \mathrm{~cm}^{-1}$, scans of $10 \mathrm{~s}$, at temperature of $20{ }^{\circ} \mathrm{C}$. Elemental analysis of the samples was carried out with an electron dispersive $\mathrm{x}$-ray (EDX) spectroscopy using a Hitachi SU8020 instrument. The morphology of synthesized samples were obtained using field emission scanning electron microscopy (FESEM) attributes with the same model as EDX. The samples were coated with platinum $(2 \mathrm{kV}, 10 \mathrm{~mA})$ and the images were taken with an accelerating voltage of electron gun $2 \mathrm{kV}$ and $\sim 16 \mathrm{~mm}$ working distance.

\section{Abrasion test}

The abrasion test is a method used to measure the performance of coated samples on the stainless steel. The coated plates were placed in a bottle loaded with an abrasive material. Two different abrasive materials were used in this testing, which were sand and molecular sieve beads. The coated substrate and abrasive material placed in the bottle and stirred for 7 hours in a milling machine with the highest rotation speed $(1000 \mathrm{rpm})$ in order to measure the coating weight loss. The sample's weight before and after the milling process was recorded to determine total weight loss.

\section{Peel adhesion test}

In order to produce a good quality coating, the strength and durability of $\mathrm{C}$ and $\mathrm{C} / \mathrm{TiO}_{2}$ coating had been studied with peel adhesion test. The coated plates were affixed with strong double-sided tape for the durations of 1,10 , and 60 minutes. After the allocated, the double-sided tapes were pulled out from the samples, in order to see whether the coating remained on the plates or stucked to the doublesided tape.

\section{RESULTS AND DISCUSSION}

Generally, $\mathrm{C}$ and $\mathrm{C} / \mathrm{TiO}_{2}$ were attached on stainless steel. In this work, for the first time, HVPSC methods utilized for powder coating. HVPSC method is different from conventional methods that usually require deposition in liquid form. This method involves the process of electrostatic deposition using electrostatic charging from an electric gun followed by curing proses. Spray coating in powder form is a simple technique and it is able due to produce a good coating.

The addition of epoxide as the adhesive for metal oxide is vital because without the presence of epoxide, the metal oxide itself is unable to attach onto the stainless steel after the curing process. As the curing process of epoxide powder occurred at $200{ }^{\circ} \mathrm{C}$ for 10 minutes, the pyrolysis temperature at $300{ }^{\circ} \mathrm{C}$ was selected as it is believed at temperature $300{ }^{\circ} \mathrm{C}$, high tendency for the epoxide powder to be converted in $\mathrm{C}$ form. Therefore, in order to study the carbon-based coating adhesion strength, the pyrolysis temperature at $300{ }^{\circ} \mathrm{C}$ for one hour was selected in this work. During the curing process, the epoxide was converted to the carbon form on a previous work on the preparation of titania-activated carbon-epoxy $\left(\mathrm{TiO}_{2} / \mathrm{AC} / \mathrm{epoxy}\right)$ in the removal of inorganic and organic impurities from water [4]. This work convinced the addition of epoxy increased the amount of carbon in the composite [4]. The addition of $\mathrm{TiO}_{2}$ is believed to improve coating adhesion strength and it is important for further application. Therefore, finding the best composition mixture of $\mathrm{TiO}_{2}$ and epoxide powder is important since too low composition of $\mathrm{TiO}_{2}$ will affect the amount of active site, while if too high may affect the efficiency of the coating performance, which may lead to lower coating adhesion.

In order to determine the best composition, various compositions of $\mathrm{TiO}_{2}$ and epoxide have been prepared. From the experimental works, $30 \mathrm{wt} \%$ or composition of $\mathrm{TiO}_{2}$ is difficult to form uniform coating due to the difficulty for the powder to flow out through the nozzle. Thus, $20 \mathrm{wt} \%$ composition of $\mathrm{TiO}_{2}$ was chosen, as it can be easily prepared.

The samples before coating and after coating (after pyrolysis process) are shown in Figure 1. In order to study the adhesion resistance of the coating, HVPSC was set up with standard setting of $50 \mathrm{kV}$ voltage with a distance between substrate and gun of $10 \mathrm{~cm}$. Using these method, all sample thickness showed in the range of 19$20 \mu \mathrm{m}$.

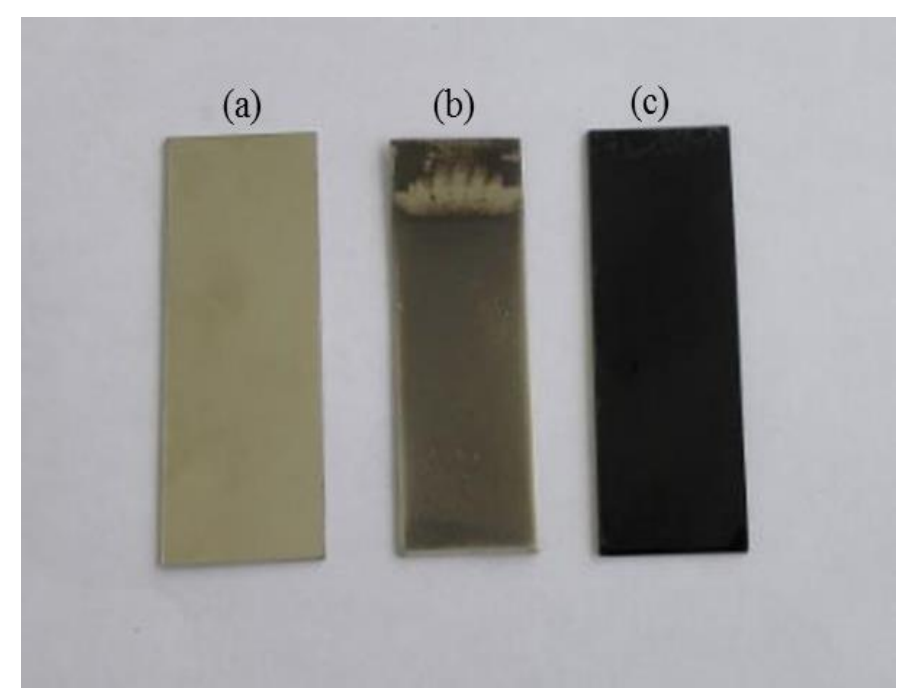

Figure 1 Images of (a) stainless steel before coating, (b) after $\mathrm{C} / \mathrm{TiO}_{2}$ coating and (c) after $\mathrm{C}$ coating.

Functional groups present in the prepared coatings are shown in Figure 2. All the principal bands of epoxide in the spectrum were in accordance with previous studies, where functional groups were observed at 2967.71, 2969.66, 1713.59, 1473, 1265.90, 1101.76 and $727.19 \mathrm{~cm}^{-1}$ indicates $\mathrm{C}-\mathrm{H} \mathrm{sp}{ }^{3}$ stretching, conjugated $\mathrm{C}=\mathrm{O}, \mathrm{C}-\mathrm{H} \mathrm{sp}^{3}$ bending, $\mathrm{C}-\mathrm{O}$, and rocking $\mathrm{CH}_{2}$ [20]. From the FTIR data, spectra (c) and (d) showed absorption band of $\mathrm{C}-\mathrm{H} \mathrm{sp}{ }^{3}, \mathrm{C}=\mathrm{O}$, and $\mathrm{C}-\mathrm{O}$. This can be explained by the tendency of epoxide to form carbon at temperature of $300{ }^{\circ} \mathrm{C}$ through the sighting of peak reduction of $\mathrm{C}-\mathrm{H}$ $\mathrm{sp}^{3}, \mathrm{C}=\mathrm{O}$, and $\mathrm{C}-\mathrm{O}$. This has been supported with the reduced peak of $\mathrm{C}-\mathrm{H} \mathrm{sp}{ }^{3}$ [21]. The presence of $\mathrm{TiO}_{2}$ in the $\mathrm{C} / \mathrm{TiO}_{2}$ coating after pyrolysis was confirmed by the peak appearing at $500-783 \mathrm{~cm}^{-1}$ which corresponded to the Ti-O bond [22]. These results are in good consistency with EDX results present in Table 1.

Element analysis of the coated plates has been carried out through EDX to study the distribution of elements present in the coatings. The data tabulated in Table 1 clearly shows only three elements were present in the samples, which are titanium (Ti), oxygen $(\mathrm{O})$, and carbon $(\mathrm{C})$. The EDX spectra in Figure 3 elements showed present in the $\mathrm{C}$ coating (without the addition of $\mathrm{TiO}_{2}$ ) were merely $\mathrm{C}$ and $\mathrm{O}$. This shows that the pyrolysis process successfully retained the carbon from the epoxide powder. From Figure 3, O element is also observed due to the effect by traces of $\mathrm{O}$ present in pyrolysis atmosphere during pyrolysis process [23]. For $\mathrm{C} / \mathrm{TiO}_{2}$ coating, the coating consists of $\mathrm{C}, \mathrm{O}$, and Ti elements that prove the addition of 20 $\mathrm{wt} \%$ titania in epoxide powder was successful. 


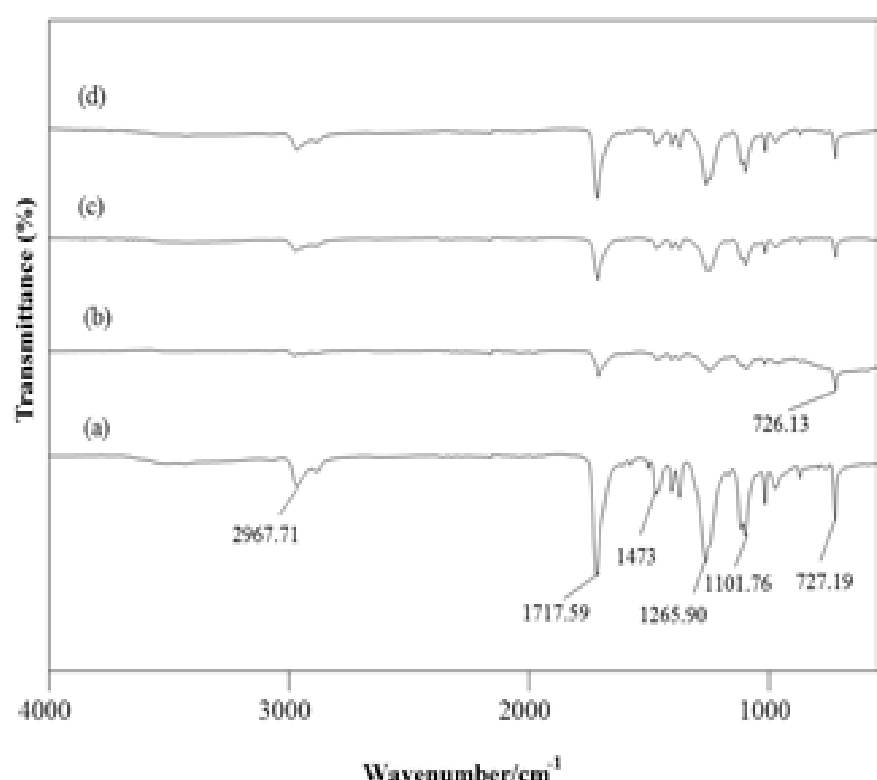

Figure 2 FTIR Spectra of (a) epoxide, (b) $\mathrm{TiO}_{2}$, (c) $\mathrm{C}$ coating and (d) $\mathrm{C} / \mathrm{TiO}_{2}$ coating.

Table 1 The atomic composition of elements present in the material coatings on the surface of stainless steels at $300^{\circ} \mathrm{C}$.

\begin{tabular}{cccc}
\hline \multirow{2}{*}{ Sample } & \multicolumn{3}{c}{ Atomic \% } \\
\cline { 2 - 4 } & $\mathrm{C}$ & $\mathrm{Ti}$ & $\mathrm{O}$ \\
\hline Carbon $(\mathrm{C})$ & 86.2 & - & 13.8 \\
Carbon-titania $\left(\mathrm{C} / \mathrm{TiO}_{2}\right)$ & 53.6 & 20.4 & 25.9 \\
\hline
\end{tabular}

(a)

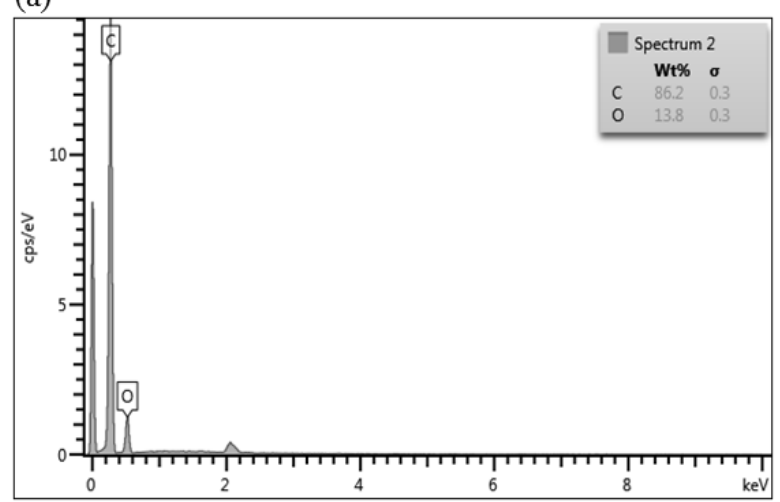

(b)

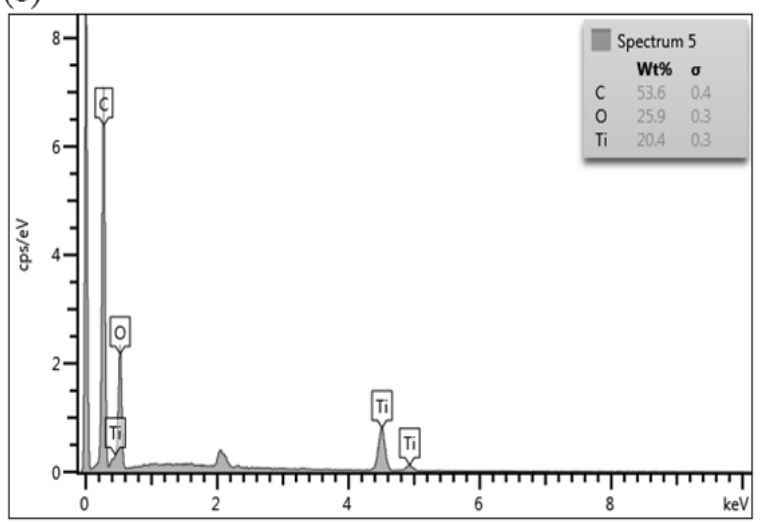

Figure 3 EDX spectra of (a) carbon coating and (b) carbon-titania coating on stainless steel plate.
Figure 4 shows the surface morphology of epoxide, $\mathrm{TiO}_{2}, \mathrm{C}$ coating and $\mathrm{C} / \mathrm{TiO}_{2}$ coating obtained using FESEM analysis. The FESEM image (a) shows the fractured surface of epoxy resin powder, while image (b) shows that the $\mathrm{TiO}_{2}$ particles are spherical shape with the size range of $56-160 \mathrm{~nm}$. In Figure 4 (c), the image showed the C was coated on stainless steel surface and the surface coating was uneven. For Figure 4 (d), it can be seen that some particles fragment on the $\mathrm{C}$ surface and it is identified as $\mathrm{TiO}_{2}$ particles. The fragment was confirmed as $\mathrm{TiO}_{2}$ due to the $\mathrm{EDX}$ spectra of $\mathrm{C} / \mathrm{TiO}_{2}$ coating shown in Figure 3. The image confirms that the $\mathrm{TiO}_{2}$ successfully attached to the carbon on the stainless after pyrolysis process.
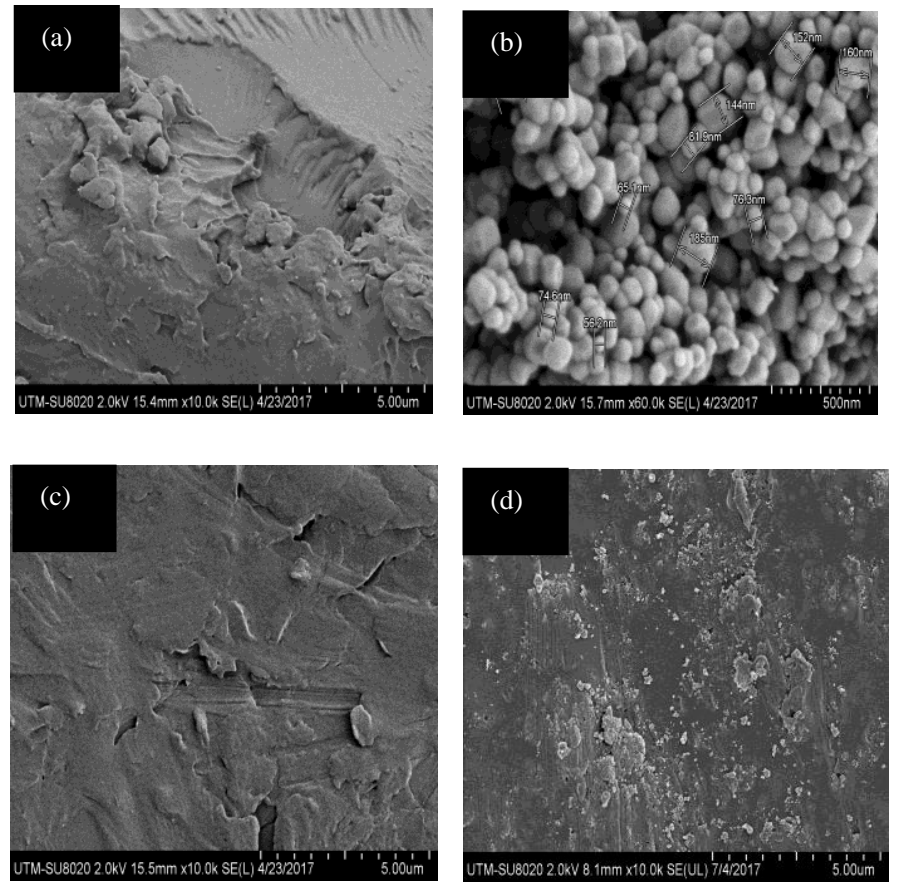

Figure 4 FESEM images of (a) epoxide powder, (b) $\mathrm{TiO}_{2}$ powder, (c) $\mathrm{C}$ coating at $300{ }^{\circ} \mathrm{C}$, and (d) $\mathrm{C} / \mathrm{TiO}_{2}$ at $300{ }^{\circ} \mathrm{C}$ on stainless steel plates.

The durability and strength of the coating are crucial in this study as high resistance coating are needed for further applications. It is purposely imposed in a controlled process using abrasive materials in abrasion testing. As a new method for $\mathrm{C}$ coated material onto stainless steel, the adhesion strength of the coating was determined and the results are shown in Table 2. After 7 hours of milling process, $\mathrm{C}$ coated on the plate resulted in low weight loss in the range of $1.8-$ 2.5 wt $\%$. On the other hand, no weight loss was measured for $\mathrm{C} / \mathrm{TiO}_{2}$ coating at the temperature $300{ }^{\circ} \mathrm{C}$. No weight loss was observed, which verifies that the attachment of $\mathrm{C} / \mathrm{TiO}_{2}$ coating on the stainless steel is strong and durable. Furthermore, no physical changes of $\mathrm{C} / \mathrm{TiO}_{2}$ coating after testing can be observed as shown in Figure 5. Nevertheless, C coating appears to be physically less stable and coating resistance efficiency is not so strong. This also is due to the occurrence of shrinkage within the $\mathrm{C}$ structure during the pyrolysis [23]. The shrinkage is likely might be due to the presence of only $\mathrm{C}$ elements with the stainless steel surface itself without any stabilizer. This phenomenon also occurred during the experimental attempts to produce $\mathrm{TiO}_{2}$ coating without any presence of epoxide, which has been unsuccessful because $\mathrm{TiO}_{2}$ cannot be attached to the stainless steel after pyrolysis.

Table 2 Abrasion test data of $\mathrm{C}$ coating and $\mathrm{C} / \mathrm{TiO}_{2}$ coating using molecular sieve and sand as the abrasive materials

\begin{tabular}{ccc}
\hline Sample & $\begin{array}{c}\text { Weight loss using } \\
\text { molecular sieve (\%) }\end{array}$ & $\begin{array}{c}\text { Weight loss using } \\
\text { sand (\%) }\end{array}$ \\
\hline $\mathrm{C} 300{ }^{\circ} \mathrm{C}$ & 1.8 & 2.5 \\
$\mathrm{C} / \mathrm{TiO}_{2} 300{ }^{\circ} \mathrm{C}$ & 0 & 0 \\
\hline
\end{tabular}


(a)

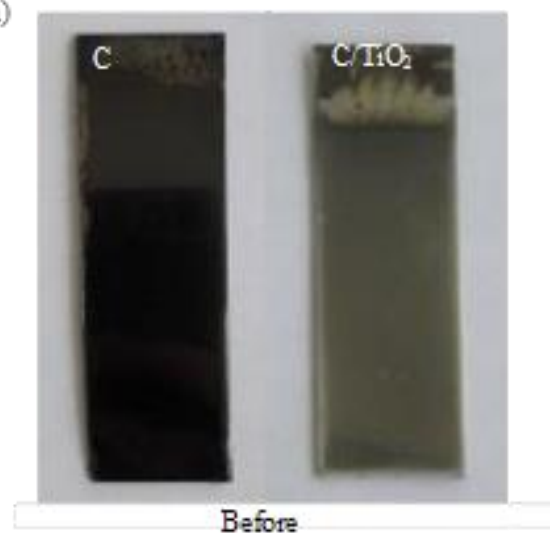

(b)

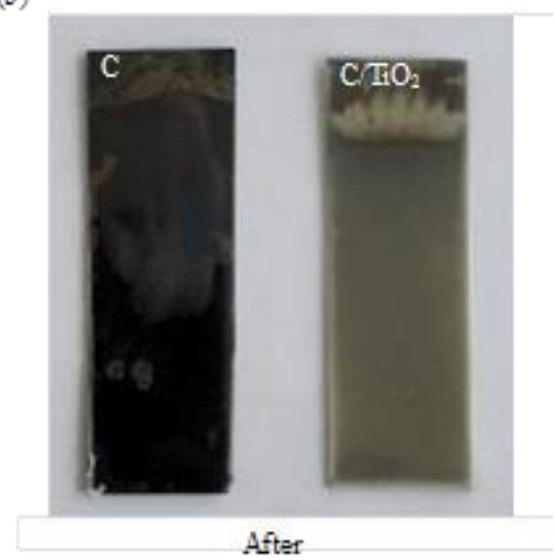

Figure 5 The images of $\mathrm{C}$ coating and $\mathrm{C} / \mathrm{TiO}_{2}$ coating on stainless steel (a) before abrasion testing and (b) after 7 hours of abrasion testing

High quality coating is extremely important for many areas of uses. The attachment of carbon was further investigated by using the peel adhesion test, but with some modifications [24]. Figure 6 shows the result of the peeling test when strong adhesive double sided tape were applied on the coated plates for different duration of time. After 1 minute application of double-sided tape on the surface of $\mathrm{C} / \mathrm{TiO}_{2}$ coated stainless steel, no coatings can be observed on the double sided tape after the peeling process. When time was increased, the results still remained the same for $\mathrm{C} / \mathrm{TiO}_{2}$ coating. However, for $\mathrm{C}$ coating, some of the coatings were attached to the double-sided tape for after 1 minute of application. As time increased, more part of the coatings were detached and attached to the adhesive tape. From the result, it can be seen that with the addition of $\mathrm{TiO}_{2}$ has assisted in strengthening the coating adhesion on the surface of the plate. This means the presence of $\mathrm{TiO}_{2}$ has functioned as a stabilizer, reinforcing the carbon-based material to prevent any shrinkage from occurring during heating, which may affect the durability of the coating.

\section{CONCLUSION}

In summary, HVPSC, as a new approach powder coating has method successfully produced a stable, strong and durable adhesion coating of $\mathrm{C}$ material on stainless steel. The formation of $\mathrm{C}$ from epoxide as the precursor has been confirmed by FTIR and EDX analysis. The attachment of $\mathrm{C} / \mathrm{TiO}_{2}$ coating was evaluated through abrasion and peel adhesion test, and showed no weight loss. Conversely, C Coating alone experienced $1.8-2.5$ wt $\%$ of weight loss. Based on the adhesion test, $\mathrm{C} / \mathrm{TiO}_{2}$ coating remained intact as compared to the $\mathrm{C}$ coating alone. Thus, it is believed that the addition of $\mathrm{TiO}_{2}$ in carbon coated stainless steel give significant impact in the coating durability, as it was still firmly attached even after removal of the adhesive tapes. Therefore, HVPSC method has been proven as a simple technique to coat materials, as $\mathrm{C} / \mathrm{TiO}_{2}$ was strongly attached on stainless steel even after pyrolysis process. Further studies on the effect of the addition $\mathrm{TiO}_{2}$ in the material are now being carried out in laboratories.

\section{(a)}
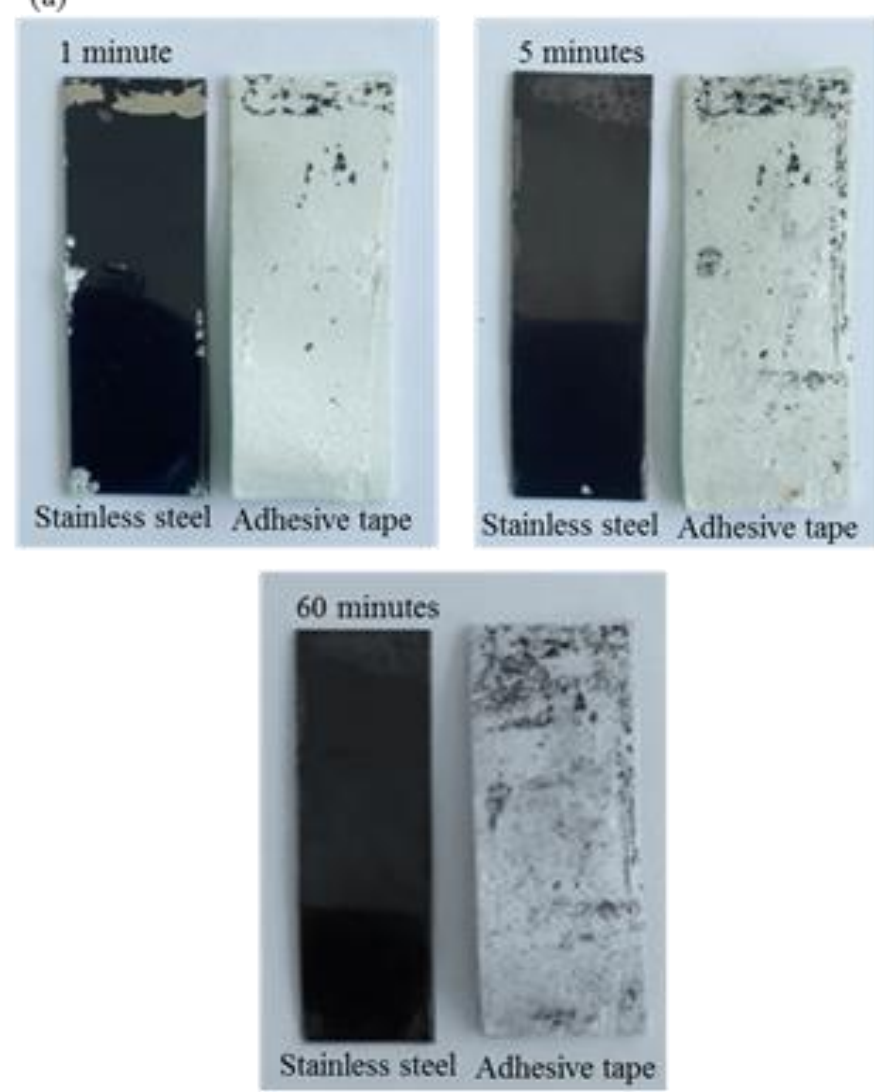

(b)
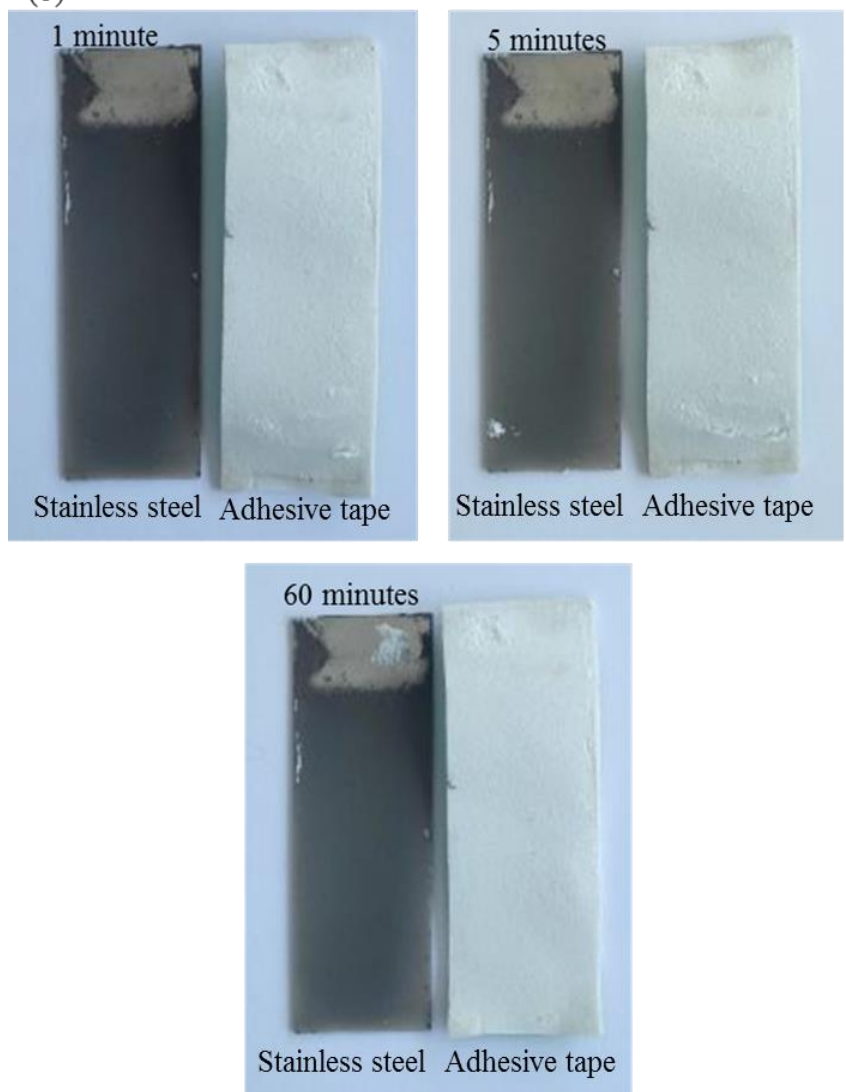

Figure 6 Images of (a) $\mathrm{C}$ coating and (b) $\mathrm{C} / \mathrm{TiO}_{2}$ coating after 1,5 and 60 minutes of adhesion test. 


\section{ACKNOWLEDGEMENT}

The authors gratefully acknowledge funding from the Ministry of Higher Education (MOHE) under Fundamental Research Grant Scheme (4F871), Universiti Teknologi Malaysia (UTM) through Research University Grant (12H79), and Longterm Research Grant Scheme (4L825).

\section{REFERENCES}

[1] Nakata, K., and Fujishima, A. 2012. $\mathrm{TiO}_{2}$ Photocatalysis: Design and applications. Photochemistry and Photobiology C: Photochemistry Reviews. 13: 169-189.

[2] Shah, A. A., Umar, A. A., Salleh, M. M. 2016. Porous (001)-faceted anatase $\mathrm{TiO}_{2}$ nanorice thin film for efficient dye-sensitized solar cell. EPJ Photovoltaics. 7: 1-7.

[3] Prasad L. K., Lafountaine, J. S., Keen, J. M., Mcginity J. W., Williams R. O. 2016. Influence of process parameters on the preparation of pharmaceutical films by electrostatic powder deposition. International Journal of Pharmaceutics. 515: 94-103

[4] Benjwal, P., and Kar K. K. 2015. Simultaneous photocatalysis and adsorption based removal of inorganic and organic impurities from water by titania/activated carbon/epoxy nanocomposite. Environmental Chemical Engineering. 3: 2076-2083.

[5] Tsumura, T., Kojitani, N., Izumi, I., Iwashita, N., Toyoda, M., Inagaki, M. 2002. Carbon coating of anatase-type $\mathrm{TiO}_{2}$ and photoactivity. Journal of Materials Chemistry. 12: 1391-1396.

[6] Ao, C. H., and Lee, S. C. 2005. Indoor air purification by photocatalyst $\mathrm{TiO}_{2}$ immobilized on an activated carbon filter installed in an air cleaner. Chemical Engineering Science. 60: 103-109.

[7] Li, Y., X. L. (2005). Photocatalytic degradation of methyl orange in sparged tube reactor with $\mathrm{TiO}_{2}$ coated activated carbon composites. Catalysis Communication. 6: 650-655.

[8] Inagaki, M. 2012. Carbon coating for enhancing the functionalities of materials. Carbon. 50: 3247-3266.

[9] Carballeira, P., and Haupert, F. 2010. Toughening effects of titanium dioxide nanoparticles on $\mathrm{TiO}_{2}$ /epoxy resin nanocomposites. Polymer Composite. 31(7): 1241-1246.

[10] Xian, G., Walter, R., Haupert, F. 2006. A synergistic effect of nano $\mathrm{TiO}_{2}$ and graphite on the tribological performance of epoxy matrix composites. Journal of Applied Polymer Science. 102 (3): 2391-2400.
[11] Sangermano, M., Matucelli, G., Amerio E. 2006. Preparation and characterization of nanostructured $\mathrm{TiO}_{2} /$ epoxy polymeric films. Macromolecular Materials and Engineering. 291(5): 517-523.

[12] Xiong, M., Zhou, S., You, B. O., Guangxin, G. U., Wu, L. 2004. Effect of preparation of titania sol on the structure and properties of acrylic resin/titania hybrid materials. Journal of Polymer Science B. 42(20): 3682-3694, 2004.

[13] Tong, Y., Li, Y., Xie, F., Ding M. 2000. Preparation and characteristics of polyimide- $\mathrm{TiO}_{2}$ Nanocomposite Film. Polymer International. 49(11) 1543-1547.

[14] Ye, F., and Ohmori, A. 2002. The photocatalytic activity and photoabsorption of plasma sprayed $\mathrm{TiO}_{2}-\mathrm{Fe}_{3} \mathrm{O}_{4}$ binary oxide coatings. Surface and Coating Technology. 150: 62-67.

[15] Hui, R., Wang, Z., Kesler, O., Rose, L., Jankovic, J., Yick, S., Maric, R., Gihosh, D. 2007. Thermal plasma spraying for SOFCs: Applications, potential, advantages, and challenges. Power Sources. 170: 308-323.

[16] Carter, C. B., Norton, M. G. 2007. Sols, Gels and Organic Chemistry. New York: Springers Science.

[17] Prasad L. K., Mcginity J. W., Williams R. O. 2016. Electrostatic powder coating: Principles and pharmaceutical applications. International Journal of Pharmaceutics. 505: 289-302.

[18] Fu, J., Zhang, H., Zhu, J. 2013. Improvement on the first pass transfer efficiency of fine polymer coating powders for corona spraying process. Advanced Powder Technology. 24: 1054-1062.

[19] Bailey, A. G. 1998. The science and technology of electrostatic powder spraying, transport and coating. Electrostatics. 45: 85-120.

[20] Gonzalez, G. M., Cabanelas, J. C., Baselga, J. 2012. Applications of FTIR on epoxy - Identification, monitoring the curing process, phase separation and water uptake. Infrared Spectroscopy - Materials Science, Engineering and Technology. In Theophanides, T. (Ed.), Spain: Intech.

[21] Tucureanu V., Matei A., Marius A. 2016. FTIR Spectroscopy for Carbon Family Study. Critical Reviews in Analytical Chemistry. 46 (6) 502-520.

[22] Lubis S., Yuliati L., Lee S. L., Sumpono I., Nur H. 2012. Improvement of catalytic activity in styrene oxidation of carbon-coated titania by formation of porous sarbon layer. Chemical Engineering Journal. 209: 486-493.

[23] Lassner, E. and Schubert, W. D. 2012. Properties, Chemistry, Technology of the Element, Alloys, and Chemical Compounds. Science. Austria: Springer science + Business media.

[24] Rouw, A. C. 1998. Model epoxy powder coating and their adhesion to steel. Progress in Organic Coatings. 34: 181-192. 